\title{
Comparative Analysis of Escape Behavior in Male, and Gravid and Non-Gravid, Female Lobsters
}

\author{
S. I. CROMARTY*, J. MELLO, AND G. KASS-SIMON† \\ Biological Sciences Department, University of Rhode Island, 100 Flagg Rd, Kingston, \\ Rhode Island 02881-0816.
}

\begin{abstract}
Few studies exist in which the parameters of a single behavior have been quantitatively compared for male and female lobsters. Here, we have examined the effects of sex and gravidity on the parameters of the escape behavior of the American lobster, Homarus americanus, elicited by a visual threat.

Both non-gravid females and male lobsters readily tailflipped in response to the stimulus, but gravid females failed, with one exception, to initiate a swim, even when stimulus strength was increased.

Although the total distance swum by males and nongravid females was not statistically different, males covered more ground in the initial power swim and during the subsequent swims than did non-gravid females. Males swam for a longer time, performing more tailflips, than females. Relative to their length and weight, males swam a greater distance at each stroke during the initial power swim and the subsequent swims, although, females might have compensated by swimming at a higher frequency. There were no significant differences in swimming velocity or acceleration, nor in the calculated force or work performed by the two sex classes (male and non-gravid females).

Therefore, apart from egg-bearing, which severely inhibits the escape response, it remains to be seen whether the subtle physiological and anatomical sexual dimorphism that produces longer and more swim strokes in
\end{abstract}

Received 14 May 1997; accepted 24 October 1997.

* Present address: Department of Neurobiology, Harvard Medical School, 220 Longwood Ave., Boston, MA 02115. E-mail: scromart@ warren.med.harvard.edu

† To whom correspondence should be addressed. E-mail: avf101@ uriacc.uri.edu

Abbreviations: FEP, Fisher exact probability test; SS1, subsequent swims of first half; SS2, subsequent swims of second half. males but higher frequency tailflips in females results in the same chances of survival for the sexes.

\section{Introduction}

There are very few quantitative studies comparing sexual differences in agonistic and avoidance behavior among lobsters (Scrivener, 1971; Stein, 1976; Atema et al., 1979; Waddy and Aiken, 1991). Anecdotal evidence and references in the literature suggest that gravid female lobsters are much more aggressive than either males or non-ovigerous females. Gravid females are described as being asocial, secretive, and defensive; when approached, they are reported to backup and raise their wide-open claws (Atema and Voigt, 1995).

Sexual dimorphism of mature individuals is well documented. Males develop larger claws, and females have broader abdomens (Templeman, 1935; McLeese and Wilder, 1964; Lang et al., 1977; Waddy and Aiken, 1991). Other physiological differences of yet-undetermined significance also exist. Males have higher hemolymph concentrations of octopamine, serotonin, tryptophan, and an unidentified compound known as compound $S$ than do females (Fadool et al., 1989).

The sexual anatomical dimorphism has led to the idea that there were sexual differences in aggressive behavior and in the establishment of dominance. The suggestion has been made that the larger claws of males were important in establishing dominance over other males or females, because lobsters with larger claws usually win in a fight (Scrivener, 1971). Alternatively, larger claws among males could be used as a sexual signal (Atema and Voigt, 1995), as is the case in crayfish where females select males with larger claws (Stein, 1976). In the female, on the other hand, sexual dimorphism has been associated 
with reproduction - the wider female abdomen increases egg-carrying capacity (Templeman, 1935; McLeese and Wilder, 1964; Waddy and Aiken, 1991).

As part of a larger study to determine whether and to what extent male and female lobsters differ in their nonsexual behaviors, we have quantitatively compared the escape response in males, gravid females, and nongravid females. Lobsters of the three "sex classes" were presented with a threatening visual stimulus. We recorded the escape hehavior sequences and post-stimuli hehaviors, which included whether animals re-approached and attacked the stimulus (after tailflipping) or whether they avoided the stimulus and continued to back away from it after the initial response. We now present evidence that among these three classes of lobsters, in addition to differences in the propensity to flee between gravid and nongravid animals, there are significant differences in the parameters of the escape response between males and non-gravid females.

\section{Materials and Methods}

\section{Animals}

Adult American lobsters (carapace length 78-85 mm) were obtained through the Rhode Island Department of Environmental Management from a nearshore lobster vessel fishing in Narragansett Bay, Rhode Island. Animals were housed at the Narragansett Bay Campus of the University of Rhode Island, in separate but connecting tanks in a free-flow seawater system, at ambient temperatures ranging from $16^{\circ}$ to $23^{\circ} \mathrm{C}$ and under an illumination cycle of $14 \mathrm{~h}$ light to $10 \mathrm{~h}$ dark.

Animals were fed three times per week on a mixed diet of squid, crab, and fish, but they were not fed for $48 \mathrm{~h}$ prior to an experiment. Four to six hours before an experiment, the animals were moved to the Kingston campus of the university, where they were placed in separate holding tanks $\left(30 \mathrm{~cm}^{3}\right)$, and visually isolated from one another. Each tank was supplied with its own air supply, and water was obtained from the same source that supplied the tanks at the Bay Campus. Individuals were kept at the same temperature $\left(20^{\circ} \mathrm{C}\right)$ as the animals held at the Bay Campus. Three hours prior to an experiment, lobsters whose claws and antennae were intact were placed in the experimental tank and left undisturbed. One hour before the experiment, the physical condition of each animal was checked. Animals were used only once and only if they moved around the tank or exhibited antennule flicking.

\section{Experiments}

Experiments were conducted from April to October to avoid possible seasonal differences in behavior. Seasonal changes in the physiology and morphology of crayfish nerve terminals have been documented (Lnenicka and Zhao, 1991). The protocol for inducing escape responses in lobsters is described in detail elsewhere (Cromarty et al., 1991). In summary, experiments were run between 1200 and $1700 \mathrm{~h}$ in an aquarium filled with filtered recirculated seawater from Narragansett Bay. Salinity was measured before each experiment and ranged between $29 \%$ and $34 \%$. Water was replaced or added as necessary to maintain salinities within this range. The experimental tank was kept between $18^{\circ}$ and $20^{\circ} \mathrm{C}$ by a Frigid Units AE-234 AG-602 chiller. The experimental setup consisted of an open-ended tank $(1.0 \mathrm{~m} \mathrm{~L} \times 0.3 \mathrm{~m} \mathrm{~W} \times 0.3 \mathrm{~m} \mathrm{H})$ emersed into a larger main tank $(2.2 \mathrm{~m} \mathrm{~L} \times 0.75 \mathrm{~m} \mathrm{~W} \times$ $0.91 \mathrm{~m} \mathrm{H})$. The layout was designed so that a threatening stimulus could be introduced at the open end of the experimental tank. A weighted wooden partition with a pulley acted as a blind (and a separation from the main tank) at the open end (Fig. 1A). To ensure that lobsters were initially at the closed, non-stimulus end, a light was placed at the open end. The partition was raised once the lobster had reached the closed end, while the light was moved to the closed, non-stimulus end. This served to 'push' the animal back towards the open (stimulus) end. A piece of PVC tubing $(0.15 \mathrm{~m} \mathrm{~L} \times 0.10 \mathrm{~m} \mathrm{~W})$ weighted with pebbles to a total weight of $1.45 \mathrm{~kg}$ served as the threatening visual stimulus. The stimulus was raised above the open end of the tank as depicted in Figure 1A. The stimulus was released into the water at a preset distance of $10 \mathrm{~cm}$ (measured from the open edge of the tank to the lobster) whenever a lobster approached the open end. In a second set of experiments, a larger stimulus of PVC tubing $(0.30 \mathrm{~m} \mathrm{~L} \times 0.20 \mathrm{~m} \mathrm{~W}$, weighing $2.45 \mathrm{~kg})$ was used on an additional set of gravid lobsters.

Cameras were placed in two positions (a Sony camcorder above the tank and a Panasonic WV-CD20 camera to the side) and experiments were recorded (Panasonic AG-6010 and Panasonic NV-8950) simultaneously from the horizontal and vertical perspectives. Video recordings of each lobster were analyzed frame-by-frame. For measurements of distance traveled, a metric grid divided into $0.5-\mathrm{cm}$ units was painted onto the side of the experimental tank. Transparent overlays on the video monitor were later used to record escape swimming distance of each animal. Distance traveled along the length of the tank was measured by using the position of the tip of the lobster's rostrum as a guide. The number of tailflips was counted. Time was automatically recorded on the videotape. An independent observer inspected all recordings and rejected runs in which the experimental parameters were not strictly adhered to; e.g., cases in which the stimulus was released closer than $10 \mathrm{~cm}$ to the experimental animal. 
A

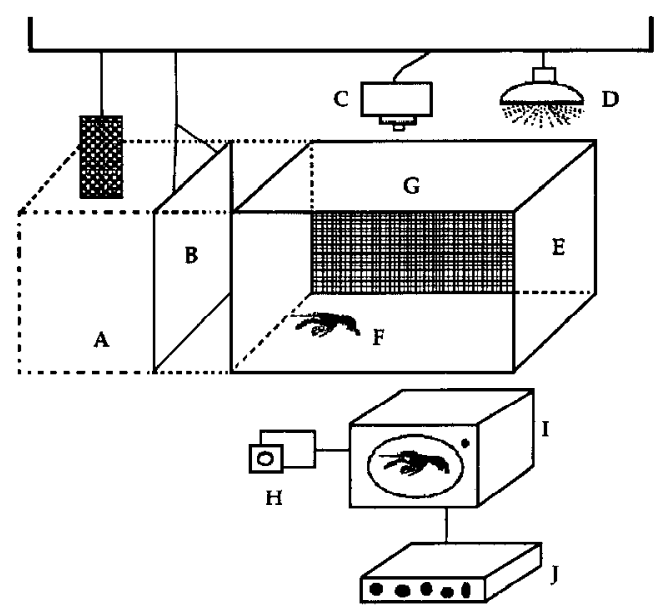

B

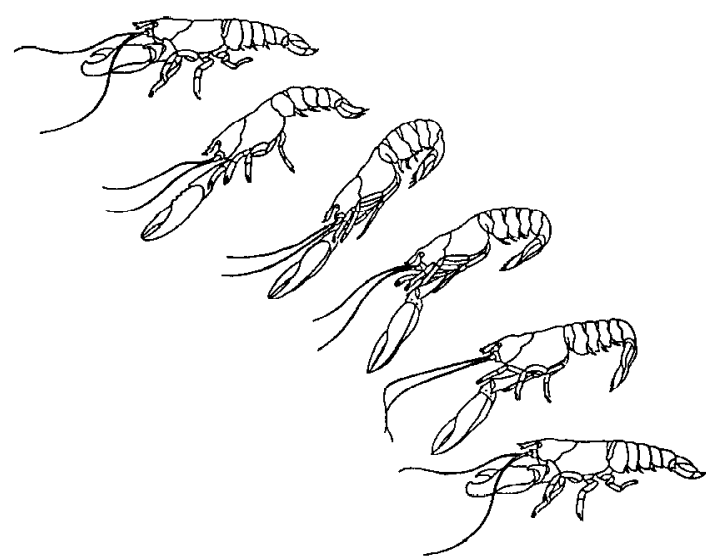

Figure 1. (A) Diagram of the experimental tank $(E)$. The stimulus was a piece of PVC tubing weighted with pebbles (A); the partition (B) was lifted while the lobster (F) was at the opposite end of the tank. A light served as the mechanism to "push" the animal to the open end, and the stimulus was released when the lobster was within $10 \mathrm{~cm}$ of the edge of the open end. The escape reaction of each lobster was photographed against a grid $(G)$ with divisions of $0.5 \mathrm{~cm}$. The recording system consisted of two cameras, one vertical (C) and one horizontal (H); monitor (I); and time-lapse VCR (J). (B) Schematic breakdown of a single tailflip as it was seen in the video analysis (original drawings done by K. Davignon, Graphics specialist, URI).

After each experiment, the animal's molt stage was determined by examining cuticular changes and setal development in the pleopods (Aiken, 1973, 1980). Only stage $\mathrm{C}$ (intermolt) animals were used, since the probability of escape depends on the molt stage of the lobster (Cromarty et al., 1991; Cromarty et al., 1995). Measurements of carapace length, cutter length, lobster weight and volume, temperature, and salinity were recorded at the end of each experimental trial. Gravid lubsters were difficult to obtain; thus, to ensure that equal numbers of animals were tested in each sex class (males, non-gravid females, gravid females), only 10 lobsters in each class (total $n=30$ ) were chosen for stimulus trials. Only one gravid lobster escaped in the first set of experiments, so an additional 10 gravid females were used in a second set of experiments with a larger stimulus. Abdominal width was not measured in the original experiments, but this measurement was later made on an additional 16 animals of each sex whose weights were equivalent to those of the original specimens.

Analysis of the escape response follows the methods used in our earlier analysis of escape behavior in juveniles (Cromarty et al., 1991). The response was broken into two elements - the initial tailflip, henceforth designated as the "power swim," and the many subsequent tailflips, designated as "subsequent swims." The number of subsequent swims in this study ranged from one to three. A tailflip, or swim, is defined as beginning immediately after the start of abdominal flexion and ending at abdominal extension (Fig. 1B). The following characteristics of the escape response were analyzed for each lobster: distance traveled (centimeters), number of tailflips, duration of the response (seconds), frequency of tailflips (tailflips/second), velocity (meters/second), acceleration (meters per second squared), force (mass $x$ acceleration), work (force $\times$ distance), distance traveled per unit of weight per tailflip (meters/kilogram/number of tailflips), distance traveled per unit of weight (meters/kilogram), and distance per lobster body length (dimensionless). The latter two parameters were calculated to determine whether variability in the weight and size of individual lobsters altered the relative significance of a parameter, even though the mean values were not significantly different among all three classes of experimental animals.

In evaluating acceleration, the added-mass forces (Batchelor, 1967) that act on accelerating bodies in fluids were ignored since these are a multiple of mass and would act equally on all animals of the same weight. Another variable which we did not include in our calculations was body rotation. Body rotation during swimming was slight in our experiments and not measurable by our methods. Animals whose gross swimming pattern deviated from a rectilinear motion were not included in the analysis. (The analysis of the escape response is meant to reflect relative changes in lobster escape behavior and not kinematic relationships such as those investigated by other researchers [Batchelor, 1967; Daniel and Meyhöfer, 1989; Nauen and Shadwick 1992].)

Each of the escape parameters was analyzed for (1) the entire escape response, (2) the initial power swim, (3) the subsequent swims over the entire subsequent swimming distance, and (4) the subsequent swims in each half of that distance, since earlier experiments showed that there were differences in the distance traveled by lobsters. We therefore divided the distance traveled in the subsequent 
swims by half and analyzed each half (Cromarty et al., 1991). Because the distance was divided equally in half for each escape sequence for each animal, no data were available to compare distance traveled between the two halves of the subsequent swims for male and non-gravid lobsters.

\section{Statistical analysis}

Differences in weight, carapace length, and cutter length among the thrce sex classes were determined by parametric analysis of variance (ANOVA). In the additional set of measured lobsters ( 16 of each sex), abdominal width, carapace length, and weight were analyzed with parametric ANOVA. The Fisher exact probability test (FEP) was used to determine differences in the probabilities of escape between the three sex classes.

A separate Kruskal-Wallis test (KW) was run for each escape parameter (except the subsequent swims). The first and second halves of the subsequent swims were compared with an ANOVA and a one-way repeated measures follow-up test (Keppel, 1982). ANOVAs were run on SPSS software (SPSS Inc., Chicago). Values were considered significant at $P \leq 0.05$ for all the statistical tests.

\section{Results}

Weight (in grams), carapace length (in millimeters), cutter length (in millimeters)

There were no significant differences in the weights (mean \pm SEM for all) of gravid (464 \pm 17.3$)$, non-gravid $(452 \pm 9.3)$, and male $(464 \pm 30.1)$ lobsters (ANOVA, $F(2,27)=0.15, P=0.86)$. No significant differences were found in the carapace lengths of gravid $(79 \pm 0.6)$, non-gravid $(80 \pm 1)$, and male $(82 \pm 2)$ lobsters (ANOVA, $F(2,27)=0.80, P=0.45)$, and similarly there were no significant differences in the cutter lengths of gravid (109 \pm 3 ), non-gravid $(110 \pm 1)$, and male (113 \pm 3 ) lobsters (ANOVA, $F(2,27)=0.92, P=0.41$ ).

\section{Abdominal width (in millimeters)}

In the set of data collected to determine if there were differences in abdominal width between the sexes, we first needed to demonstrate that these lobsters were similar in weight and size (carapace length) to those used in the escape behavior experiments.

No differences were found between the weights (mean \pm SEM, in grams) of the measured females $(461 \pm 9.4$; $n=16)$ and the experimental females $(460 \pm 9.5 ; n=$ 20); ANOVA, $F(1,34)=0.11, P=0.92$. Similarly, no differences were found in the weights of the measured males $(421 \pm 18.9 ; n=16)$ and the experimental males $(464 \pm 30.1 ; n=10)$; ANOVA, $F(1,24)=1.81, P=$
0.19 . Furthermore, there were no differences in carapace length (mean \pm SEM, in millimeters) - male or female between the two groups. Females: measured (79.6 \pm 0.5 ; $n=16)$ versus experimental $(79.7 \pm 0.6 ; n=20)$; ANOVA, $F(1,34)=0.003, P=0.95$. Male: measured $(77.9$ $\pm 1.3 ; n=16)$ versus experimental $(82.0 \pm 2.0 ; n=10)$; ANOVA, $F(1,24)=2.72, P=0.11$. Therefore, abdominal widths from this data set were analyzed and are assumed to reflect the abdominal widths of the animals that were used in the experiments on escape behavior.

In this data set, significant differences in abdominal width were found between male $(42.93 \pm 0.52)$ and female $(53.38 \pm 0.97)$ lobsters (ANOVA, $F(1,30)=89.33$, $P=0.0001$ ), suggesting that a similar sexual dimorphism also existed in the experimental escape animals.

\section{Escape behavior in response to a threatening stimulus}

The probability of responding to a threat with an escape response was unequal among the three sex classes (Table 1). Gravid female lobsters were significantly less likely to escape than either males (Fisher exact probability test, FEP, $P<0.0004$ ) or non-gravid females (FEP, $P<$ $0.0001)$ when presented with a stimulus $(0.30 \mathrm{~m} \mathrm{~L} \times$ $0.15 \mathrm{~m} \mathrm{~W}$ ) weighing $1.45 \mathrm{~kg}$. No gravid lobsters escaped when presented with this stimulus. Eight of ten males and five of ten non-gravid females tailflipped when presented with this stimulus. The difference was not significantly different (FEP, $P=0.17$ ).

When 10 gravid females were presented with a larger and heavier stimulus $(0.30 \mathrm{~m} \mathrm{~L} \times 0.15 \mathrm{~m} \mathrm{~W})$, weighing $2.45 \mathrm{~kg}$, only one gravid animal tailflipped. This female traveled approximately $80 \mathrm{~cm}$, tailflipping six times with a large loss of eggs. The larger stimulus was not presented to males or non-gravid females since the smaller stimulus was sufficient to initiate their escape behavior.

Table I

Escape and post-threat behavior of each sex class after the small escape stimulus was presented (ten lobsters in each class were tested)

\begin{tabular}{lccccc}
\hline \hline & \multirow{2}{*}{$\begin{array}{c}\text { Immediate } \\
\text { Sesponse }\end{array}$} & & \multicolumn{3}{c}{ Secondary responses } \\
\cline { 2 - 2 } \cline { 5 - 6 } \multicolumn{1}{c}{ Sex class } & Tailflip* $^{*}$ & & Back up & Approach & $\begin{array}{c}\text { Approach } \\
\text { and attack }\end{array}$ \\
\hline Gravid females & 0 & & 6 & 4 & 4 \\
Non-gravid females & 5 & & 3 & 7 & 4 \\
Males & 8 & & 5 & 5 & 4 \\
\hline
\end{tabular}

* Some lobsters initially tailtlipped and then reapproached and/or attacked the stimulus. 


\section{Post-stimulus behavior}

After the stimulus was presented, lobsters would either (1) tailflip away from the stimulus, (2) tailflip first and then continue backing slowly away, (3) tailflip first and then approach, (4) tailflip, and then approach and attack. "Approach" is distinguished from "approach and attack" by the absence of any physical contact on the part of the lobster and might just as well be due to curiosity as to agonistic causes, unlike "approach and attack," which clearly suggests agonistic responses. For example, four lobsters in each of the three sex classes (that had originally tailflipped), immediately returned, approached and attacked the stimulus (Table I).

Post-threat behaviors were evaluated by Fisher exact probability tests $(2 \times 2$ contingency tables $)$. No significant differences were found in post-threat behavior among the three sex classes. All probability values were greater than $P=0.15$, regardless of whether the comparisons were between gravid and non-gravid females, gravid females and males, or non-gravid female and males.

\section{Escape parameters for male and non-gravid adult lobsters}

Only non-gravid females and males were compared because only one gravid female could be induced to tailflip.

Total escape response (initial power swim plus subsequent swims). Total distance traveled during an escape, number of tailflips, swimming velocity, acceleration, force, work, distance traveled per kilogram of weight,
A

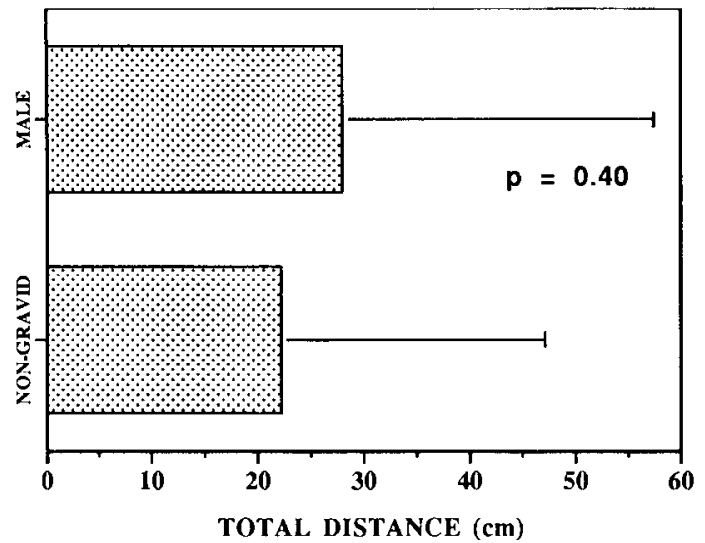

C

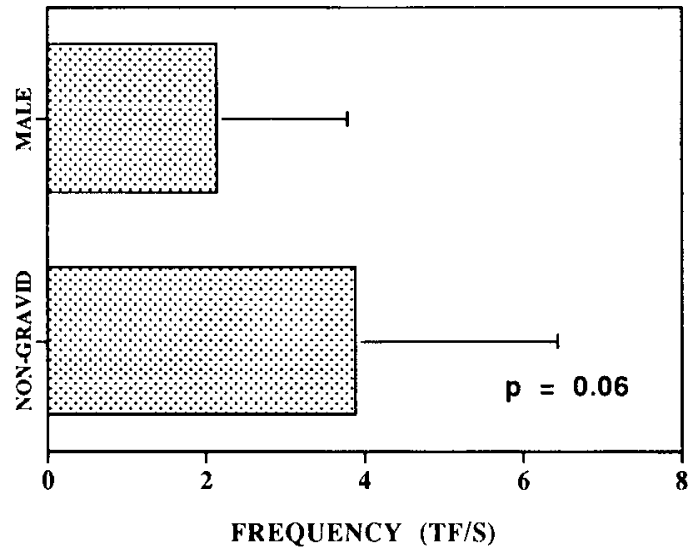

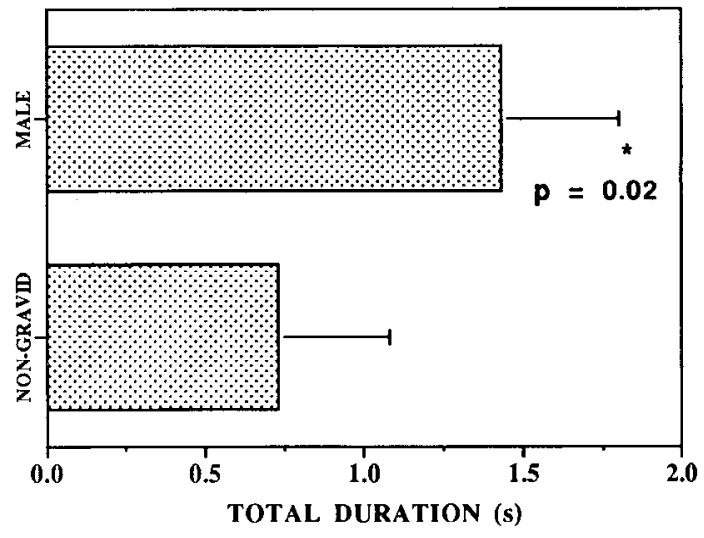

D

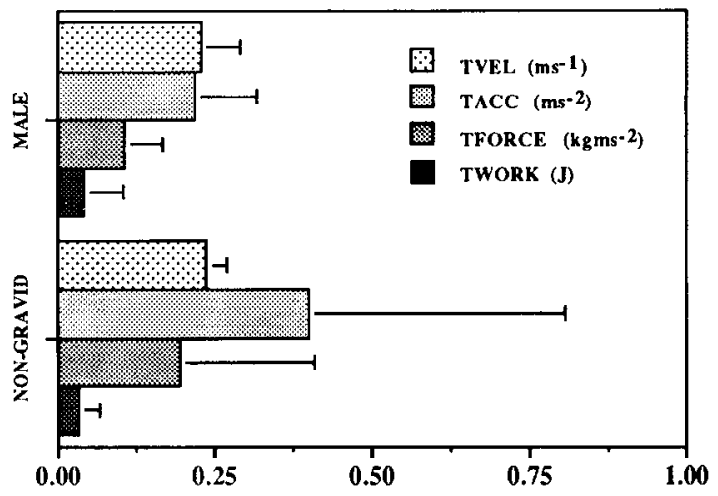

Figure 2. Comparison of parameters (mean $\pm \mathrm{SD}$ ) of the entire escape response for male $(n=8)$ and non-gravid female $(n=5$ ) lobsters. An asterisk (*) indicates significant differences at $P \leq 0.05$. (A) Distance traveled in centimeters $(\mathrm{cm})$. (B) Duration of swimming sequence in seconds (s). (C) Frequency $(\mathrm{TF} / \mathrm{s})$. (D) $\mathrm{TVEL}=$ total velocity $(\mathrm{m} / \mathrm{s}) ; \mathrm{TACC}=$ total acceleration $\left(\mathrm{m} / \mathrm{s}^{2}\right) ;$ TFORCE $=$ total force (newtons $\left[\mathrm{kg} /\left(\mathrm{m} / \mathrm{s}^{2}\right]\right)$; and TWORK $=$ total work (joules [force $\times$ distance]). 
and distance traveled per lobster body length were not significantly different (KW, $P>0.05$; see Fig. $2 \mathrm{~A}$ and 2D for examples). The total time spent escaping was, however, significantly greater for male lobsters $(\mathrm{KW}, P$ $=0.02$, Fig. 2B). Distance traveled per kilogram of weight per tailflip was not significantly different $(\mathrm{KW}, P=0.40)$. Although the difference was not significant at the 0.05 level, non-gravid females may perform more tailflips per second than male lobsters (KW, $P=0.06$, Fig. 2C).

Initial power swim. Distance traveled was significantly higher for males than for non-gravid females (KW, $P=0.04$; Fig. 3A). Although males tended to have longer power swim durations, the difference was not significantly different at the $P=0.05$ level $(\mathrm{KW}, P=0.08$, Fig. 3B). Distance swum per body length and distance swum per kilogram of weight were also both significantly
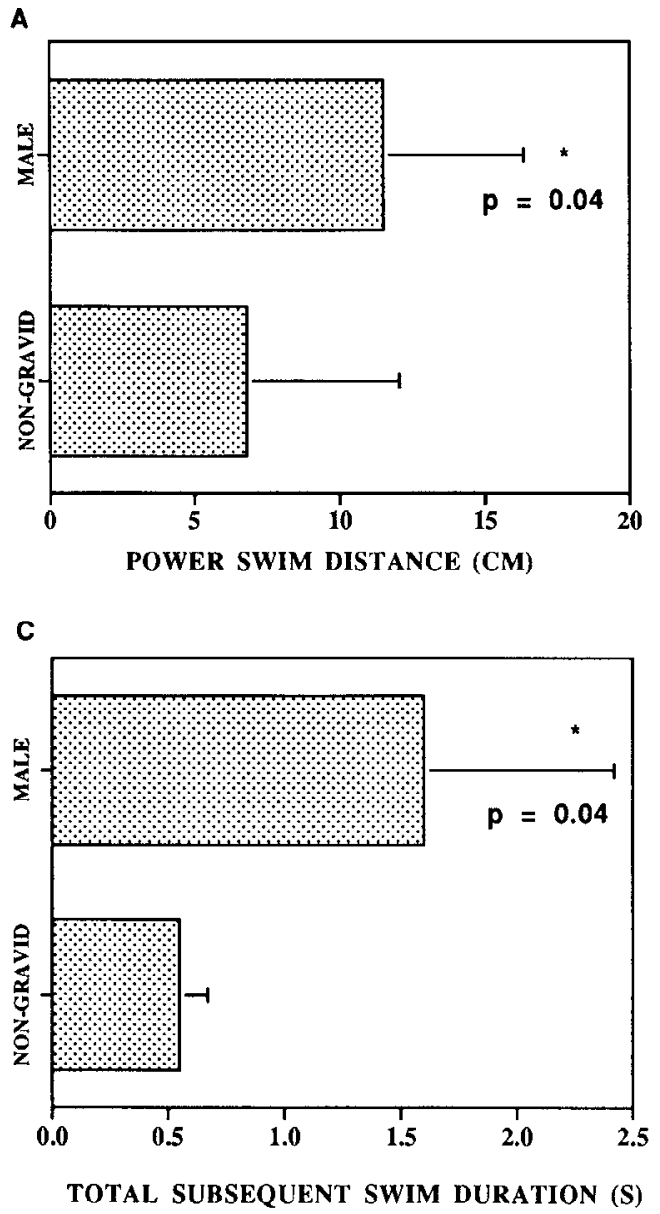

greater for males (KWs, $P=0.03$ and 0.05 respectively). Although the mean values for power swim velocity, acceleration, force, and work all were higher for male lobsters, the differences were not significant, because of the large variance within each class.

Total subsequent swims. The time spent in subsequent swims and the number of tailflips were significantly higher for male lobsters than for non-gravid females (KWs, $P=0.04$ and 0.03 , Fig. $3 \mathrm{C}$ and D respectively). Distance swum per body length and distance swum per kilogram of weight for the subsequent swims were also statistically higher for males (KWs, $P=0.01$ and 0.02 respectively). No other parameters were found to be statistically different for the total subsequent swims.

Comparison of SS1 and SS2 between and within sex classes. In the first half of the subsequent swims (SS1),

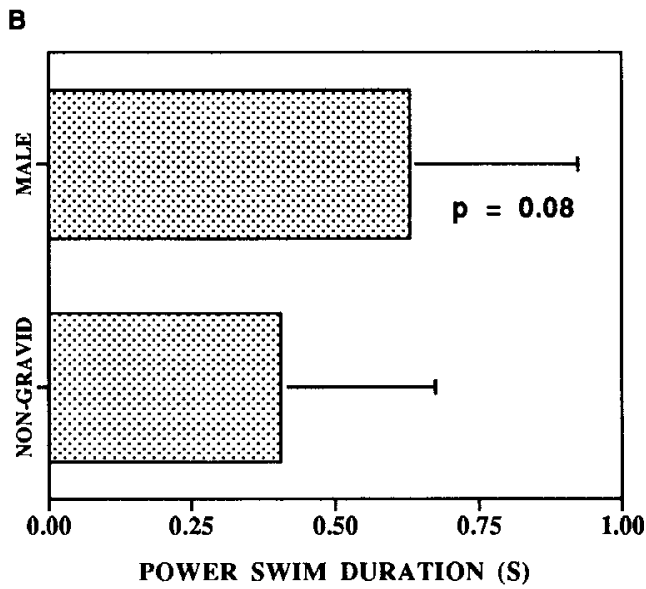

D

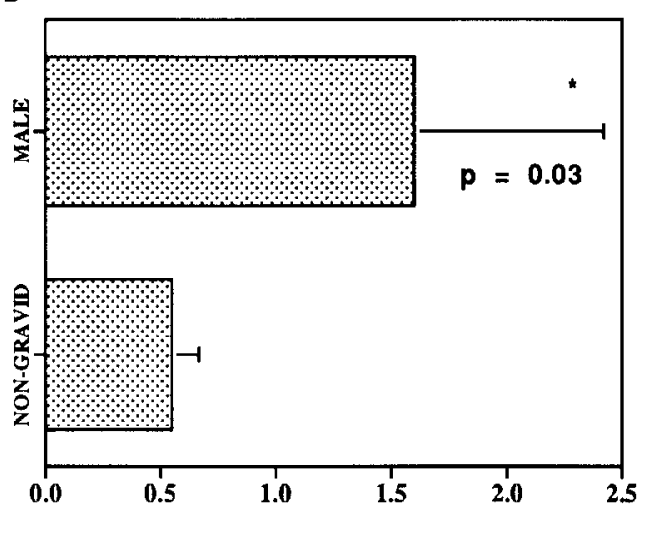

TOTAL NUMBER OF SUBSEQUENT TAILFLIPS

Figure 3. Comparison of parameters (mean $\pm \mathrm{SD}$ ) of the power swim and total subsequent swims for male $(n=8)$ and non-gravid female $(n=5)$ lobsters. An asterisk $\left(^{*}\right)$ indicates that the results are significantly different at $P<0.05$. (A) Distance traveled during the power swim in centimeters $(\mathrm{cm})$. (B) Time spent escaping during the power swim in seconds (s). (C) Duration of swimming sequence during the total subsequent swims in seconds (s). (D) Number of tailflips during the total subsequent swims in centimeters $(\mathrm{cm})$. 
male lobsters spent more time escaping (duration) and produced more tailflips (KWs; $P=0.05$ and 0.03, Fig. $4 \mathrm{~A}$ and $\mathrm{C}$ respectively). Similar differences were found in the second half of the subsequent swims (SS2), with males again spending more time escaping and taking more tailflips (KWs, $P=0.04$ and 0.04, Fig. 4B and D respectively). When SS1 and SS2 were compared to each other, for each sex, no significant differences were observed. There was no reduction in any of the parameters between the first and second halves of the subsequent swims for either males or females. No other parameters, either of total subsequent swims or within SS1 or SS2, were statistically different.

\section{Discussion}

Among crustaceans, there are four major morphological and physiological determinants that affect agonistic and escape behavior: age, size, molt-stage, and sex. Thus, large adults are more likely to win in aggressive encounters (Scrivener, 1971) and are dominant over smaller juveniles (Atema and Cobb, 1980); and soft-shelled premolt animals win over soft-shelled postmolt animals (Tamm and Cobb, 1978). In avoidance or escape behavior, small juveniles swim faster and farther than large adults, which tend not to respond to a threat with escape swimming (Cromarty et al., 1995). In addition, soft-shelled juveniles swim faster and farther than hard-shelled juveniles (Cromarty et al., 1991), but hard-shelled adults swim farther than soft-shelled ones (Cromarty et al., 1995).

In this study we have shown that males and non-gravid females are equally likely to initiate escape swimming when threatened. The probability of eliciting escape behavior in gravid females is, however, significantly lower. These animals, like large adult males ( $>600 \mathrm{~g}$ ), are essentially inhibited from swimming, even when presented
A

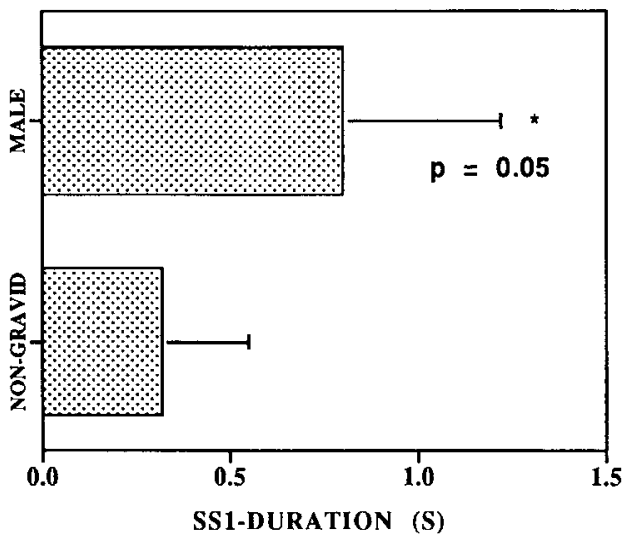

B

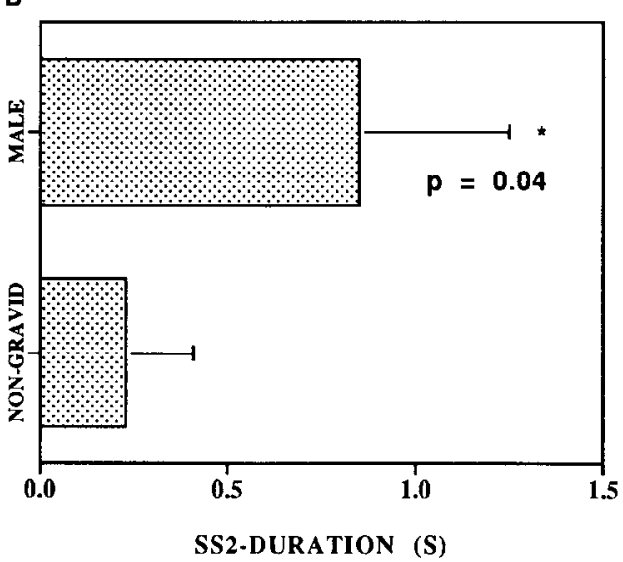

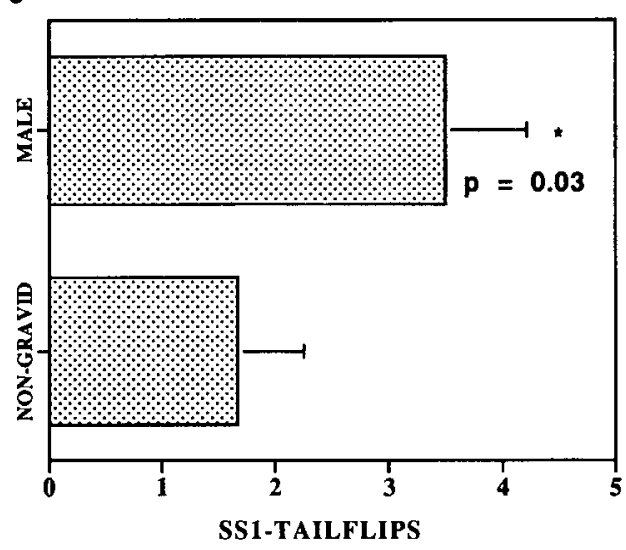

D

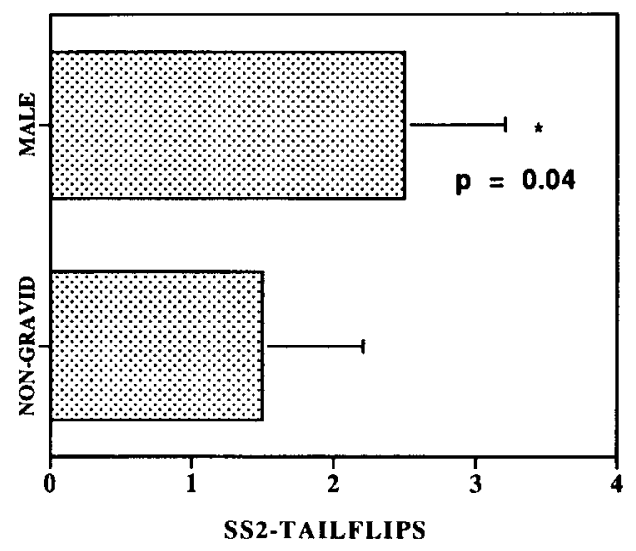

Figure 4. Comparison of parameters (mean \pm SD) of the first (SS1) and second (SS2) halves of subsequent swims for male $(n=8)$ and non-gravid female $(n=5)$ lobsters. An asterisk (*) indicates these results are significantly different at $P \leq 0.05$. (A, B) Duration, in seconds (s), of swimming sequence during SS1 (A) and SS2 (B). (C, D) Number of tailflips during SS1 (C) and SS2 (D). 
with larger stimuli (see Cromarty et al., 1997). The physiological bases for these inhibitions are not yet known and may or may not be due to the same physiological mechanisms; these could involve inhibition of (a) sensory input to the central nervous system (Watson, 1992, for a review) or (b) neurons within the central nervous system (Beall et al., 1990), or at peripheral synapses (Schwanke et al., 1990; Cromarty et al., 1995; Cromarty and KassSimon, 1996), or in both locations.

Although the same physiology may ultimately be involved in both cases, the adaptive significance in each instance appears to be different. In the case of the adult male lobsters, the large size of the claws could make escape swimming more difficult (Lang et al., 1977), but would increase the odds of a favorable outcome in confrontations with a predator or conspecific opponent. In the case of the ovigerous females, escape swimming would have a deleterious effect. The single gravid female that responded to a threat with swimming lost many eggs, underscoring the idea that in this case, swimming inhibition evolved to ensure reproductive success.

Differences in the characteristics of escape behavior between non-gravid females and males are more subtle. Although the total distance that each group swam did not prove to be different, males covered more ground than did non-gravid females, both in the single initial power swim and in the sum of the subsequent swims. This suggests that, like the molt-related differential effects on the power swim and subsequent swims found in juvenile lobsters (Cromarty et al., 1991), sex-related differential effects on the neuronal pathway appear to be mediating the two components of the escape swimming. It thus appears that, as in crayfish (Wine and Krasne, 1972), in lobster, escape behavior is most likely mediated by both giant (initial power swim) and non-giant fibers (subsequent swims).

Male lobsters appeared to outperform females in several other parameters. On average, they swam for a significantly longer time by performing more tailflips than non-gravid females. They also covered a greater distance relative to their body length and weight than females, in both the initial power swim and in the sum of the subsequent swims. Females, on the other hand, may have compensated by swimming at a higher frequency than males. Since the weight averages for all groups were not statistically different, these performance differences may reflect differences in body architecture, muscle properties (composition or physiology), titers of circulating neurohumors, or a combination of these factors. The broader females (see results) would experience more drag, so that the distance covered for each body length would be reduced; males, on the other hand, might have greater abdominal strength and thus be more efficient swimmers. Moreover, since males have higher circulating concentrations of putative excitatory neurohormones (Fadool et al., 1989), their actions might enhance central or peripheral synapses (Kravitz, 1988, for review; Schwanke et al., 1990). In this regard, although our experiments were run on isolated individuals, it should be noted that in crayfish (Yeh et al., 1996), the lateral giant neuron, which is responsible for escape responses elicited by tactile or mechanical deflcction of the telson, is affected by the animal's social experience, with dominant animals having an enhanced response to stimuli.

However, although there may be subtle sex-related differences in the characteristics of escape swimming, significant differences between the two sexes were absent not only in the total distance swum, but also in the velocity or acceleration of the swim, and in the calculated force or work performed. Our relatively small sample size may preclude a definitive conclusion about sexual differences in escape behavior. A larger sample size, or an analysis of additional escape parameters, might reveal differences between the sexes, given that there are inherent sexual abdominal dimorphisms.

It remains to be seen, therefore, whether the anatomical and physiological sexual differences that result in more and longer tailflips in males, but perhaps a higher frequency of swimming in females, have any effect on the relative chances of the sexes for survival.

\section{Acknowledgments}

We thank Kathy Castro of the University of Rhode Island Fisheries Department for her assistance in collecting lobsters and measuring their abdomens. We also thank Dr. Michael Clancy and Malia Schwartz for critiquing an earlier draft of the manuscript. This research was supported by a Whitehall Foundation grant to G.K.S., and Sigma Xi and Lerner Gray grants to S.I.C.

\section{Literature Cited}

Aiken, D. E. 1973. Proecdysis, setal development, and molt prediction in the American lobster (Homarus americanus). J. Fish. Res. Board Can. 30: 1334-1337.

Aiken, D. E. 1980. Molting and growth. Pp. 91-163 in The Biology and Management of Lobsters. vol. 1, J. S. Cobb and B. F. Phillips, eds. Academic Press, New York.

Atema, J., and J. S. Cobb. 1980. Social behavior. Pp. 409-450 in The Biology and Management of Lobsters. vol. 1, J. S. Cobb and B. F. Phillips, eds. Academic Press, New York.

Atema, J., and R. Voigt. 1995. Behavior and sensory biology. Pp. 313-348 in The Biology of the Lobster, Homarus americanus. J. Factor, cd. Academic Press, New York.

Atema, J., S. Jacobsen, E. Karnofsky, S. Olesko-Szuts, and L. Stein. 1979. Pair formation in the lobster, Homarus americanus: behavioral development, and mating. Mar. Behav. Physiol. 6: 277-296. 
Batchelor, G. K. 1967. An Introduction to Fluid Dynamics. Cambridge University Press, London.

Beall, S. P., D. J. Langley, and D. H. Edwards. 1990. Inhibition of escape tailflip in crayfish during backward walking and the defense posture. J. Exp. Biol. 152: 577-582.

Cromarty, S. I., and G. Kass-Simon. 1996. Electrophysiological correlates of the escape response in the adult American lobster ( $\mathrm{Ho}$ marus americanus) over the molt cycle. Soc. Neurosci. Abstr. 26: 440.

Cromarty, S. I., J. S. Cobb, and G. Kass-Simon. 1991. Behavioral analysis of the escape response in juvenile American lobsters, $\mathrm{Ho}$ marus americanus over the molt cycle. J. Exp. Biol. 158: 565-581.

Cromarty, S. I., J. S. Cobb, and G. Kass-Simon. 1995. Adult and juvenile lobsters (Homarus americanus), differ markedly in the neuromuscular physiology and behavior of the escape response over the molt cycle. Soc. Neurosci. Abstr. 25: 201.

Daniel, T. L., and E. Meyhöfer. 1989. Size limits in escape locomotion of carridean shrimp. J. Exp. Biol. 143: 245-265.

Fadool, D. A., P. R. Brown, J. S. Cobb, and G. Kass-Simon. 1989. HPLC analysis of lobster haemolymph over the molt cycle. Comp. Biochem. Physiol. 93C: 225-230.

Keppel, G. 1982. Design and Analysis: A Researcher's Handbook, 2nd Ed. Prentice Hall, Englewood Cliffs, New Jerscy.

Kravitz, E. A. 1988. Hormonal control of behavior: amines and the biasing of behavioral output in lobsters. Science 241: 1775-1782.

Lang, F., C. K. Govind, W. J. Costello, and S. I.Greene. 1977. Developmental neuroethology: changes in escape and defensive behavior during growth of the lobster. Science 197: 682684 .

Lnenicka, G. A., and Y. Zhao. 1991. Seasonal differences in the physiology and morphology of crayfish motor terminals. J. Neurobiol. 22: $561-569$.
McLeese, D. W., and D. G. Wilder. 1964. Lobster storage and shipment. Bull. Fish. Res. Board Can. No. 147, 69 pp.

Nauen, J. C., and R. E. Shadwick. 1992. Biomechanics of tail-flipping by the spiny lobster Panulirus interruptus. Am. Zool. 32: 127A.

Schwanke, M. L., J. S. Cobb, and G. Kass-Simon. 1990. Synaptic plasticity and humoral modulation of neuromuscular transmission in the lobster claw opener during the molt cycle. Comp. Biochem. Physiol. 97C: 143-149.

Scrivener, J. C. E. 1971. Agonistic behavior of the American lobster, Homarus americanus (Milne-Edwards). Fish. Res. Board. Can. Tech. Rep. 235: 1-128.

Stein, R. A. 1976. Sexual dimorphism in crayfish chelae: functional significance linked to reproductive activities. Can. J. Zool. 54: 220227.

Tamm, G. R., and J. S. Cobb. 1978. Behavior and the crustacean molt cycle: changes in aggression of Homarus americanus. Science 200: $79-81$.

Templeman, W. 1935. Local differences in the body proportions of the lobster Homarus americanus. J. Biol. Board Can. 2: 223-226.

Waddy, S. L., and D. E. Aiken. 1991. Mating and insemination in the American lobster, Homarus americanus. Pp. 126-144 in Crustacean Sexual Biology, R. T. Bauer and J. W. Martin, eds. Columbia University Press, New York.

Watson, A. H. D. 1992. Presynaptic modulation of sensory afferents in the invertebrate and vertebrate nervous system. Comp. Biochem. Physiol. 103A: 227-239.

Wine, J. J., and F. B. Krasne. 1972. The organization of escape behaviour in the crayfish. J. Exp. Biol. 56: 1-18.

Yeh, S.-R., R. A. Fricke, and D. H. Edwards. 1996. The effect of social experience on serotonergic modulation of the escape circuit of crayfish. Science 271: 366-369. 